\section{Dementia \\ and Geriatric}

Cognitive Disorders
Dement Geriatr Cogn Disord 2018;46:322-334

DOI: $10.1159 / 000492920$

Received: April 27, 2018

Accepted: August 14, 2018

(C) 2018 S. Karger AG, Basel

www.karger.com/dem

\title{
Systematic Review and Meta-Analysis of Prevalence in Post-Stroke Neurocognitive Disorders in Hospital-Based Studies
}

\author{
Mélanie Barbay ${ }^{a} \quad$ Momar Diouf $^{b} \quad$ Martine Roussel $^{a}$ \\ Olivier Godefroy ${ }^{a}$ GRECOGVASC study group \\ aDepartment of Neurology and Laboratory of Functional Neurosciences (EA 4559), \\ Amiens University Hospital, Amiens, France; ${ }^{b}$ Department of Biostatistics, Amiens University \\ Hospital, Amiens, France
}

\section{Keywords}

Dementia $\cdot$ Mild cognitive impairment $\cdot$ Infarct $\cdot$ Hemorrhage $\cdot$ Stroke $\cdot$ Diagnosis

\begin{abstract}
Background/Aims: Post-stroke neurocognitive disorders (post-stroke NCD) have been reported with a very variable prevalence. Methods: Based on a systematic literature search, hospital-based studies published between January 1990 and September 2015 were selected when they reported the prevalence of total, mild, and major post-stroke NCD diagnosed by using specified criteria. Factors affecting prevalence were assessed using meta-regression analysis. Results: Among the 7,440 references evaluated, 16 hospital-based studies were selected, corresponding to a total of 3,087 patients. The overall prevalence of total post-stroke NCD was 53.4\% (95\% Cl: 46.9-59.8): 36.4\% for mild post-stroke NCD (95\% Cl: 29-43.8) and $16.5 \%$ (95\% Cl: 12.1-20.8) for major post-stroke NCD. The overall prevalence was mainly influenced by the threshold score used for categorization $(p=0.0001)$ and, in the subgroup of studies using a conservative threshold (i.e., $\leq 7$ th percentile), by the recurrent stroke rate $(p=0.0005)$. The prevalence of major post-stroke NCD was mainly influenced by age ( $p=$ 0.003). Conclusion: More than half of stroke survivors experience post-stroke NCD, corresponding to mild post-stroke NCD in two-thirds of cases and major post-stroke NCD in one-third of cases. Harmonization of stroke assessment and cognitive score thresholds is urgently needed to allow more accurate estimation of post-stroke NCD prevalence, especially mild post-stroke NCD.


Barbay et al.: Meta-Analysis of Post-Stroke Cognitive Disorders

\section{Introduction}

The prevalence of post-stroke neurocognitive disorders (post-stroke NCD) has been documented in a large number of studies, mostly focusing on major post-stroke NCD (i.e., post-stroke dementia). A systematic review and a meta-analysis [1, 2] have shown that the prevalence of major post-stroke NCD ranges from 7 to $67.3 \%$, depending on the study setting (hospital- or population-based studies), stroke type (ischemic or hemorrhagic), the prevalence of pre-stroke dementia and recurrent stroke, and the post-stroke interval [2]. In contrast, the prevalence of mild post-stroke NCD and total post-stroke NCD (i.e., mild + major poststroke NCD) has been less extensively studied and has not been systematically reviewed. However, the presence of post-stroke NCD, regardless of its severity, constitutes an independent risk factor for dependence and institutionalization [3, 4], highlighting the need to determine the prevalence of post-stroke NCD regardless of its severity. Factors associated with the prevalence of NCD also need to be identified. We hypothesized that stroke characteristics and the diagnostic criteria of cognitive impairment both influence the prevalence of post-stroke cognitive impairment. We deliberately focused on hospital-based cohorts because they correspond to populations entering a management circuit designed to reduce disability. In addition, diagnosis on mild NCD requires a comprehensive neuropsychological assessment, which does not form a part of usual standard of care for stroke patients.

The objective of this study was to assess the prevalence of total, mild, and major poststroke NCD by a meta-analysis based on a systematic review of hospital-based studies and to determine factors affecting this prevalence.

\section{Methods}

\section{Eligibility Criteria}

A systematic review was conducted according to the Meta-Analysis of Observational Studies in Epidemiology criteria [5].Studies published between January 1990 and September 2015 were eligible when they (1) included $\geq 50$ consecutive patients (2) initially hospitalized for ischemic or hemorrhagic stroke, (3) assessed $\geq 1$ month post-stroke (4) using a neuropsychological battery, (5) reported the prevalence of total, mild, and major post-stroke NCD determined (6) according to specified criteria of mild and major NCD. Studies including patients with transient ischemic attack were eligible when they also included cerebral infarct or hemorrhage and when the prevalence of each condition was reported. Studies in which evaluation was limited to screening tests were not eligible. When data from the same cohort were reported in several papers, the study reporting the largest sample fitting our eligibility criteria was selected. Corresponding authors were contacted when necessary.

\section{Procedure}

The literature search was conducted using MEDLINE, Web of Science, and Embase to retrieve papers that met the eligibility criteria. Searches were based on combinations of the following terms in the title or abstract: "cognit*, neuropsychol*, dement*, MCI" with "stroke, cerebral infarct, cerebral hemorrhag*, cerebral ischem*". The reference lists of selected papers as well as subsequent citations of these papers were also examined. All titles and abstracts were reviewed by two investigators (M.B. and O.G.) and the full texts of eligible papers were examined.

\section{Data Extraction}

The following data were extracted from published papers, protocols, appendices, and post hoc analyses and, when necessary, from direct contact with the authors: author, year, country, name of cohort, mean age, sex ratio (percentage of men), proportion of patients with low education level in the study (defined as primary education or $<9$ years of education or illiteracy), stroke subtypes (transient ischemic attack, infarct, hemorrhage) and their frequencies, the inclusion of patients with recurrent stroke and the recurrent stroke rate, the assessment of pre-stroke cognitive impairment (previously diagnosed dementia or systematic 
Fig. 1. Literature searches and re-

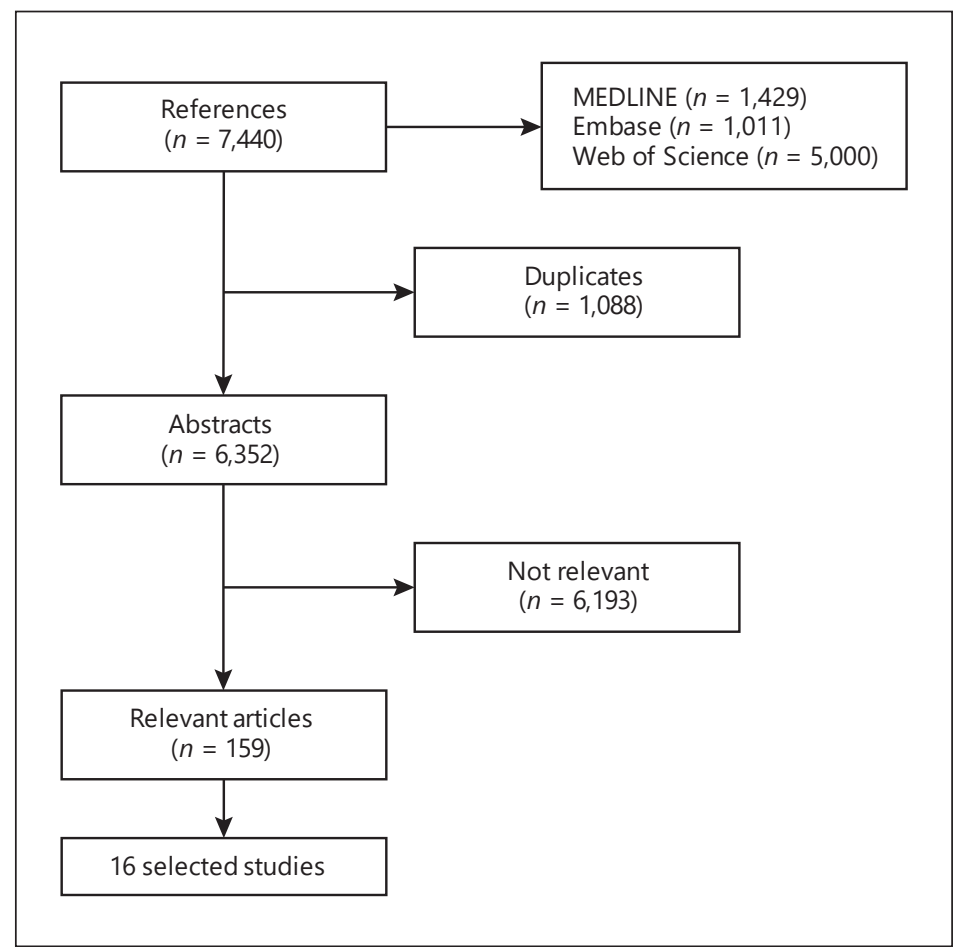
sults.

assessment of pre-stroke cognitive status) and its frequency, the mean interval between stroke and the cognitive assessment, diagnostic criteria of mild and major NCD, the threshold (defined as $\leq 7$ th percentile, i.e., 1.5 SD, or not) used to categorize cognitive scores as normal versus impaired, the method used to define cutoff scores (published scores or scores defined on a control population and its size), the use of methods to control for false-positive rate (adjustment of the number of impaired scores, computation of domain scores or global score), number of patients effectively evaluated using the neuropsychological battery, and number of patients classified in the mild and major post-stroke NCD subgroups.

\section{Statistical Analysis}

Prevalence of NCD and its variance were computed for each study. Due to heterogeneity between studies, meta-analysis was performed with a random effect model using restricted maximum likelihood (REML) estimates [6]. Variance within and between studies was therefore used to compute the variance of the final pooled prevalence. Heterogeneity was assessed by the inconsistency index $I^{2}$ and the Q test [7]. Statistical heterogeneity was declared for a $p$ value $\leq 0.05$ with the $Q$ test. Forest plots were used to visualize the prevalence in each study and the combined estimated prevalence with their $95 \%$ confidence intervals (95\% CI). Publication bias was assessed graphically using funnel plots and tested using Egger's method [8]. Study characteristics influencing the resulting prevalence were evaluated by REML random effect metaregression [9]. Pooled odds ratios were calculated for patients with a random effects analysis when there was evidence of heterogeneity ( $p \leq 0.1$ ). The effect of each factor on the reduction of variability between studies was calculated. A $p$ value $\leq 0.05$ was considered for statistical significance. All statistical analyses were performed with R software version 3.1.0 and SAS version 7.12.

\section{Results}

From the 7,440 references extracted by the literature search (Fig. 1), 159 articles were analyzed and 16 studies were selected, corresponding to a total of 3,087 patients. Ineligible studies on post-stroke NCD included cross-sectional studies resulting in variable post-stroke intervals [10], non-consecutive patients [11-16], studies which failed to report the rates of 
Table 1. Characteristics of the 16 studies selected

\begin{tabular}{|c|c|c|c|c|c|c|c|c|c|c|c|c|c|}
\hline Cohorts [Ref.] & $\begin{array}{l}\mathrm{Pa}- \\
\text { tients, } \\
n\end{array}$ & $\begin{array}{l}\text { Mean } \\
\text { age, } \\
\text { years }\end{array}$ & $\begin{array}{l}\text { Male, } \\
\%\end{array}$ & $\begin{array}{l}\text { Exclusion } \\
\text { of } \\
\text { recurrent } \\
\text { stroke }\end{array}$ & $\begin{array}{l}\text { Stroke } \\
\text { recur- } \\
\text { rence, } \\
\%\end{array}$ & $\begin{array}{l}\text { Exclusion } \\
\text { of pre- } \\
\text { stroke } \\
\text { dementia }\end{array}$ & $\begin{array}{l}\text { Pre- } \\
\text { stroke } \\
\text { dementia, } \\
\%\end{array}$ & $\begin{array}{l}\text { Stroke } \\
\text { type }\end{array}$ & $\begin{array}{l}\text { In- } \\
\text { farct, } \\
\%\end{array}$ & $\begin{array}{l}\text { Post- } \\
\text { stroke } \\
\text { interval, } \\
\text { months }\end{array}$ & $\begin{array}{l}\text { Criteria } \\
\text { of mild } \\
\text { NCD }\end{array}$ & $\begin{array}{l}\text { Criteria of } \\
\text { major NCD }\end{array}$ & $\begin{array}{l}\text { Thres- } \\
\text { hold } \\
\leq 7 \text { th per- } \\
\text { centile }\end{array}$ \\
\hline New York, USA [51] & 251 & 72 & 43 & No & 6.4 & No & 9.6 & IS & 100 & 3 & Other & DSM-III-R & Yes \\
\hline $\begin{array}{l}\text { Maastricht, The } \\
\text { Netherlands [53] }\end{array}$ & 154 & 68.4 & 55 & Yes & 0.0 & Yes & NA & IS, ICH & 89.4 & 6 & Petersen & $\begin{array}{l}\text { DSM-IV, NINDS } \\
\text { AIREN }\end{array}$ & No \\
\hline Bergamo, Italy [54] & 110 & 65.1 & 65 & Yes & 0.0 & Yes & NA & IS & 100 & 3.5 & Other & NINDSAIREN & NA \\
\hline Finland [55] & 451 & 71.2 & 51 & No & 22.2 & No & 12.2 & IS & 100 & 3 & Other & DSM-IV & No \\
\hline Lisbon, Portugal [56] & 220 & 59 & 55 & No & NA & Yes & NA & IS, ICH & 75.9 & 3 & Other & NINDSAIREN & Yes \\
\hline Madrid, Spain [57] & 209 & 69.1 & 53 & No & NA & No & 12.6 & IS & 88.4 & 3 & Other & DSM-IV & Yes \\
\hline Sydney, Australia [58] & 160 & 72.1 & 61 & Yes & 0.0 & Yes & 0 & IS, TIA & 83.8 & 4.5 & Petersen & VASCOG & No \\
\hline Hong Kong, China [31] & 75 & 71 & 52 & No & 22.7 & No & NA & IS & 100 & 3 & Other & DSM-IV & NA \\
\hline Mexico, Mexico [59] & 107 & 56 & 62 & Yes & 0.0 & Yes & NA & $\begin{array}{l}\text { IS, ICH, } \\
\text { CVT }\end{array}$ & 84.0 & 3 & CHSA & $\begin{array}{l}\text { NINDSAIREN/ } \\
\text { DSM4 }\end{array}$ & Yes \\
\hline Singapore [60] & 318 & 59.8 & 70 & No & 19.2 & Yes & $\mathrm{NA}$ & IS, TIA & 78.6 & 4.5 & Petersen & DSM-IV & Yes \\
\hline South Korea [41] & 353 & 63.9 & 61 & No & 18.4 & No & 0.1 & IS & 100 & 3 & Other & DSM-IV & No \\
\hline Norway [61] & 184 & 72 & 51 & Yes & 0.0 & Yes & NA & $\begin{array}{l}\text { IS, ICH, } \\
\text { TIA }\end{array}$ & 76.4 & 12 & Petersen & ICD10 & NA \\
\hline Sweden [62] & 149 & 81 & 35 & No & 13.4 & Yes & NA & IS, ICH & 94.5 & 18 & CHSA & DSM-III-R & No \\
\hline Chile [63] & 101 & 72 & 58 & No & 20.0 & Yes & 26.7 & IS, ICH & 85.0 & 12 & Other & Other & NA \\
\hline India [64] & 102 & 59.4 & 74 & Yes & 26.5 & Yes & NA & IS, ICH & 88.2 & 6 & CSHA & NINDS-AIREN & NA \\
\hline Nigeria [65] & 143 & 60.4 & 57 & No & 12.6 & Yes & 11.2 & IS, ICH & 79.5 & 3 & VASCOG & DSM-IV & Yes \\
\hline
\end{tabular}

NCD, neurocognitive disorders, Lac, lacunar stroke, CVT, cerebral venous thrombosis, IS, ischemic stroke, ICH, intracerebral hemorrhage, TIA, transient ischemic attack, NA, not available.

both mild and major post-stroke NCD, and studies that did not use a neuropsychological battery [12-14, 17-44].

Selected studies (Table 1 ) were characterized by heterogeneity of general characteristics, with age ranging from 56 to 81 years (weighted mean: 67 years), a slight male predominance (weighted frequency: 55.8\%; range: 34.9-73.5), low education level in 34.4\% (8.870.4) (online suppl. Table S1; for all online suppl. material, see www.karger.com/ doi/10.1159/000492920) with a mean schooling of 6.96 (4.7-10.1) years. Regarding stroke type, 6 studies only included patients with infarct, while the remaining 10 studies included mixed stroke types, in which infarcts represented 89.9\% (75.9-100) and stroke due to either cerebral infarct or hemorrhage represented 96\% (78.6-100) of the pooled population. Recurrent strokes were excluded in 6 studies and represented $12.95 \%(0-26.5)$ of the pooled population. Pre-stroke cognitive impairment was excluded in 11 studies ( 8 on clinical grounds and 3 based on a formal assessment) and was observed with a weighted mean frequency of $7.54 \%$ (0-26.7). Cognitive assessment was performed after a mean post-stroke interval of 5 months (3-18). The mean Mini-Mental State Examination score (computed using mean scores available in 10 studies) was 24.9 (20.4-27.8). The most commonly used diagnostic criteria were DSM-IV criteria $(n=8)$ for dementia and the cognitive impairment, no-dementia $(n=$ 11) subgroup of the Canadian Study of Health and Aging classification [4] for mild cognitive impairment. Cutoff scores for test interpretation were based on published norms in 8 studies and were computed using control groups in 4 of these studies with a mean sample size of 


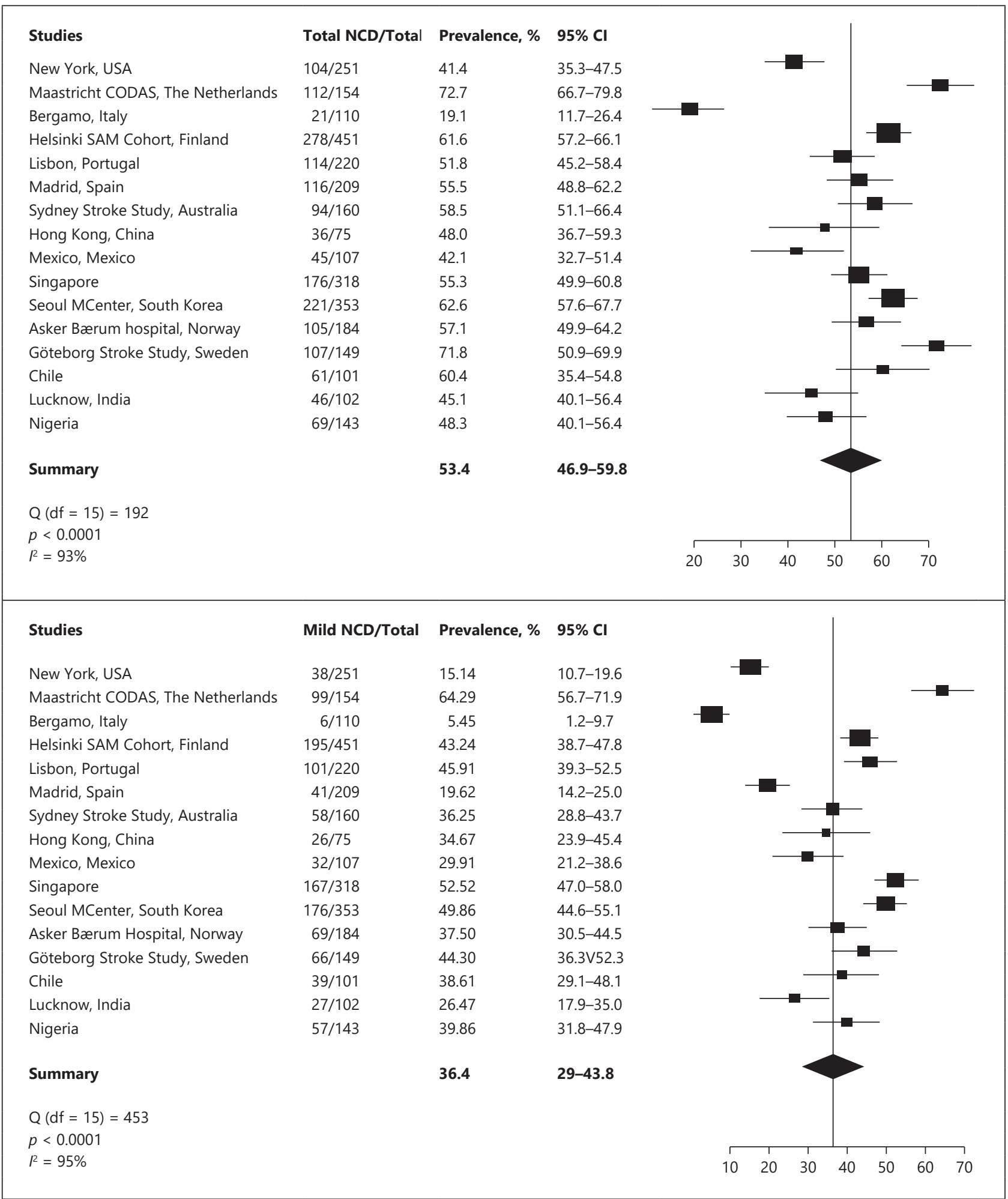

Fig. 2. Prevalence of total (top), mild (middle), and major (bottom) post-stroke neurocognitive disorders (NCD).

(Figure continued on next page.) 


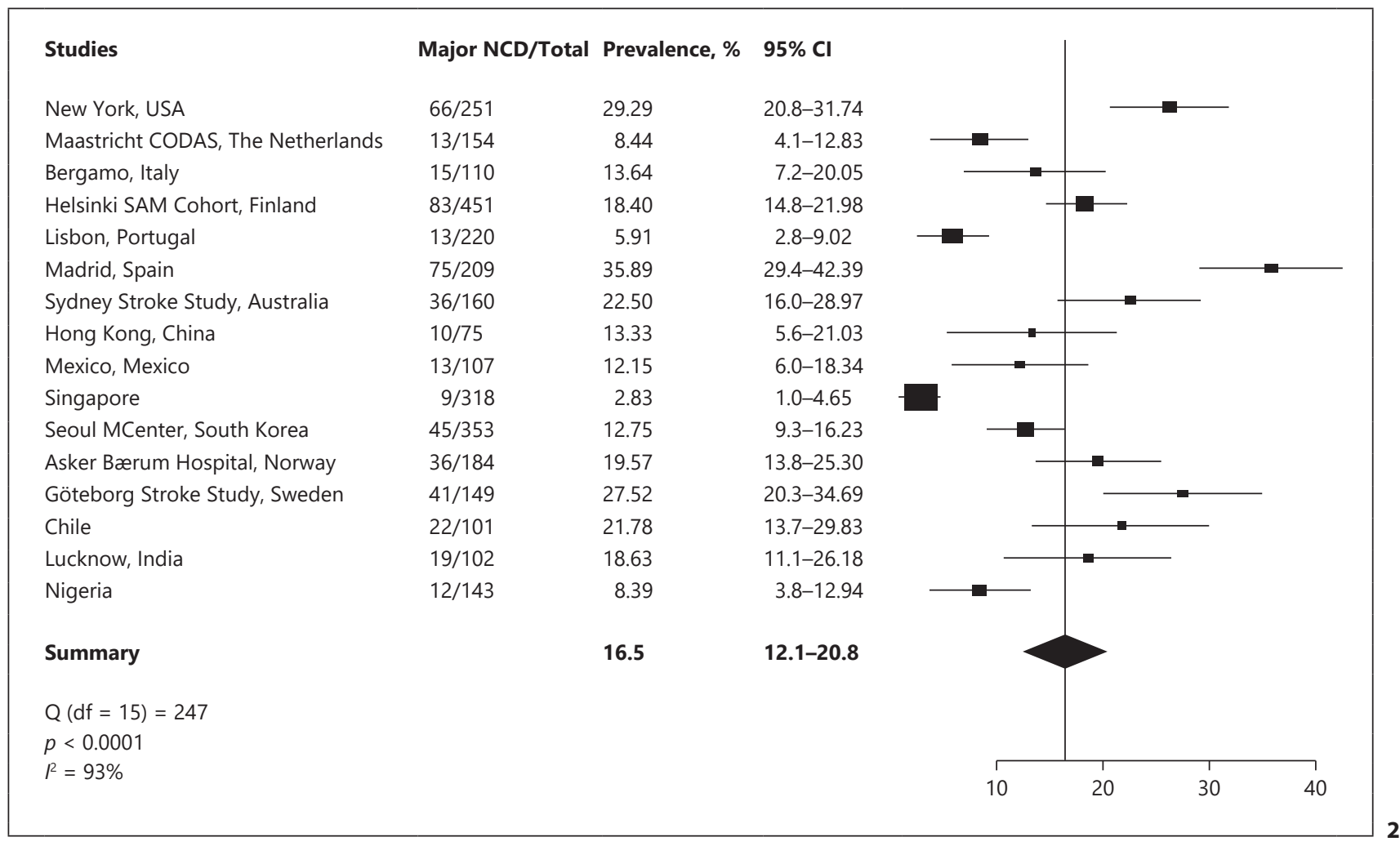

Table 2. Factors influencing the frequency of post-stroke neurocognitive disorders (NCD)

\begin{tabular}{|c|c|c|c|c|c|c|c|}
\hline & Age & $\begin{array}{l}\text { Prevalence } \\
\text { of pre-stroke } \\
\text { dementia }\end{array}$ & $\begin{array}{l}\text { Parenchymal } \\
\text { lesions }\end{array}$ & $\begin{array}{l}\text { Stroke } \\
\text { recurrence }\end{array}$ & $\begin{array}{l}\text { Low } \\
\text { education } \\
\text { level }\end{array}$ & $\begin{array}{l}\text { Post-stroke } \\
\text { interval }\end{array}$ & $\begin{array}{l}\text { Threshold } \\
\text { score } \leq 7 \text { th } \\
\text { percentile }\end{array}$ \\
\hline \multicolumn{8}{|l|}{ Total NCD } \\
\hline Coefficient & $0.84 \pm 0.47$ & $0.21 \pm 0.51$ & $-0.21 \pm 0.41$ & $0.25 \pm 0.39$ & $0.05 \pm 0.17$ & $1.4 \pm 0.7$ & $-15.9 .0 \pm 3.7$ \\
\hline$p$ & 0.0748 & 0.4 & 0.6 & 0.5 & 0.8 & 0.053 & $0.0001^{*}$ \\
\hline Reduction of variability & $-13.4 \%$ & $+23.1 \%$ & $+5.5 \%$ & $+21.8 \%$ & $-37.8 \%$ & $-16 \%$ & $-82.7 \%$ \\
\hline \multicolumn{8}{|l|}{ Mild NCD } \\
\hline Coefficient & $0.01 \pm 0.57$ & $-0.17 \pm 0.60$ & $-0.32 \pm 0.45$ & $0.32 \pm 0.42$ & $-0.06 \pm 0.25$ & $0.61 \pm 0.86$ & $-12.0 \pm 7.50$ \\
\hline$p$ & 0.98 & 0.77 & 0.48 & 0.44 & 0.82 & 0.47 & 0.108 \\
\hline Reduction of variability & $+7.1 \%$ & $+72.4 \%$ & $+3.5 \%$ & $+44.2 \%$ & $+11.2 \%$ & $+3.5 \%$ & $-28.9 \%$ \\
\hline \multicolumn{8}{|l|}{ Major NCD } \\
\hline Coefficient & $1.06 \pm 0.36$ & $0.54 \pm 0.33$ & $0.27 \pm 0.37$ & $0.18 \pm 0.29$ & $0.20 \pm 0.17$ & $0.36 \pm 0.70$ & $-2.00 \pm 7.19$ \\
\hline$p$ & $0.003^{*}$ & 0.11 & 0.4 & 0.5 & 0.25 & 0.6 & 0.78 \\
\hline Reduction of variability & $-38.6 \%$ & $-48.7 \%$ & $+4.7 \%$ & $-34.6 \%$ & $-18.1 \%$ & $+5.5 \%$ & $+5.5 \%$ \\
\hline
\end{tabular}

186.8 (42-539). The threshold was available in 11 studies and was $\leq 7$ th percentile in 6 studies.

The pooled prevalence (Fig. 2) was 53.4\% (95\% CI: 46.9-59.8) for total post-stroke NCD, $36.4 \%$ (95\% CI: 29-43.8) for mild post-stroke NCD, and 16.5\% (95\% CI: 12.1-20.8) for major post-stroke NCD (Fig. 2). Substantial heterogeneity $\left(I^{2} \geq 93 \%\right.$, all) was observed across studies in the 3 analyses. A publication bias resulting in a low prevalence of major post-stroke NCD in studies based on small sizes cannot be excluded (online suppl. Fig. S2). 
Fig. 3. Overall prevalence of poststroke neurocognitive disorders (PSNCD) according to threshold.

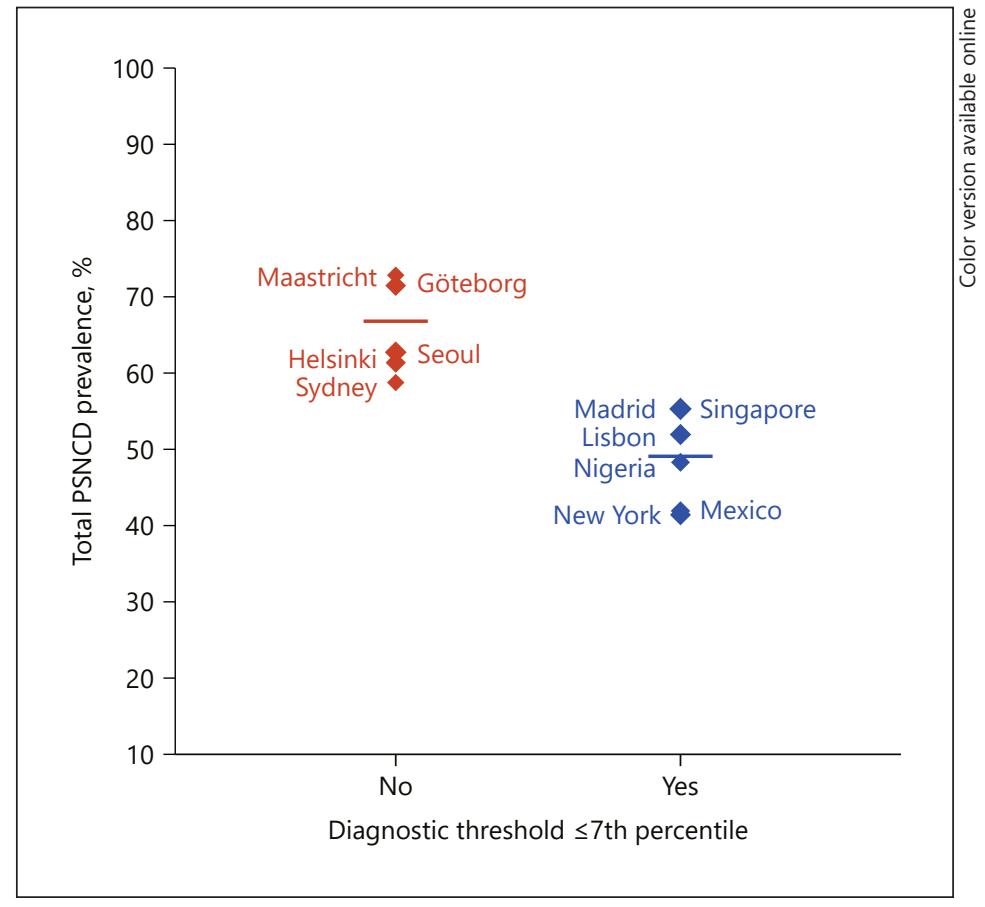

Meta-regression analysis was performed in the subgroup of 11 studies providing factors submitted to meta-regression (online suppl. Table 1), representing a total of 2,515 patients. Meta-regression analysis was significant for total post-stroke NCD (Table 2) due to the threshold used for score categorization ( $p=0.0001)$ with a strong tendency $(p=0.053)$ for increasing prevalence with longer post-stroke interval. The use of a threshold $>7$ th percentile (Fig. 3 ) was associated with a $14.1 \%$ increase of the estimated prevalence $(64.1 \mathrm{vs.} 49.9 \%$ for threshold $\leq 7$ th percentile). In view of the strong effect of the threshold on the resulting prevalence of total post-stroke NCD and the marked heterogeneity of studies using a threshold $>7$ th percentile, meta-regression was conducted on a subgroup of 4 studies using a threshold $\leq 7$ th percentile and showed that the variability across studies was explained by the recurrent stroke rate (estimated coefficient: $0.76 \pm 0.22 ; p=0.0005$; reduction of variability: $100 \%$ ), but not by the prevalence of pre-stroke dementia (estimated coefficient: $0.03 \pm 0.66 ; p=0.9689$ ) (Fig. 4). No factor was significantly associated with mild post-stroke NCD. Meta-regression analysis of major post-stroke NCD (Table 2) showed a significant effect of age ( $p=0.003$ ) with a higher prevalence in studies including older patients, corresponding to a prevalence increment of approximately $1.1 \%$ per year (online suppl. Fig. S3).

\section{Discussion}

The main result of this study is that $53.4 \%$ (95\% CI: 46.9-59.8) of patients surviving a stroke experience post-stroke NCD, corresponding to mild post-stroke NCD in 36.4\% (95\% CI: 29-43.8) and major NCD in 16.5\% (95\% CI: 12.1-20.8) of cases. To our knowledge, this is the first study to estimate the pooled prevalence of total and mild post-stroke NCD. Although most previous studies and pooled analyses have focused on major post-stroke NCD, the overall prevalence of post-stroke NCD is the outcome of interest, as the presence of poststroke NCD, regardless of its severity, has been shown to be associated with mortality, depen- 


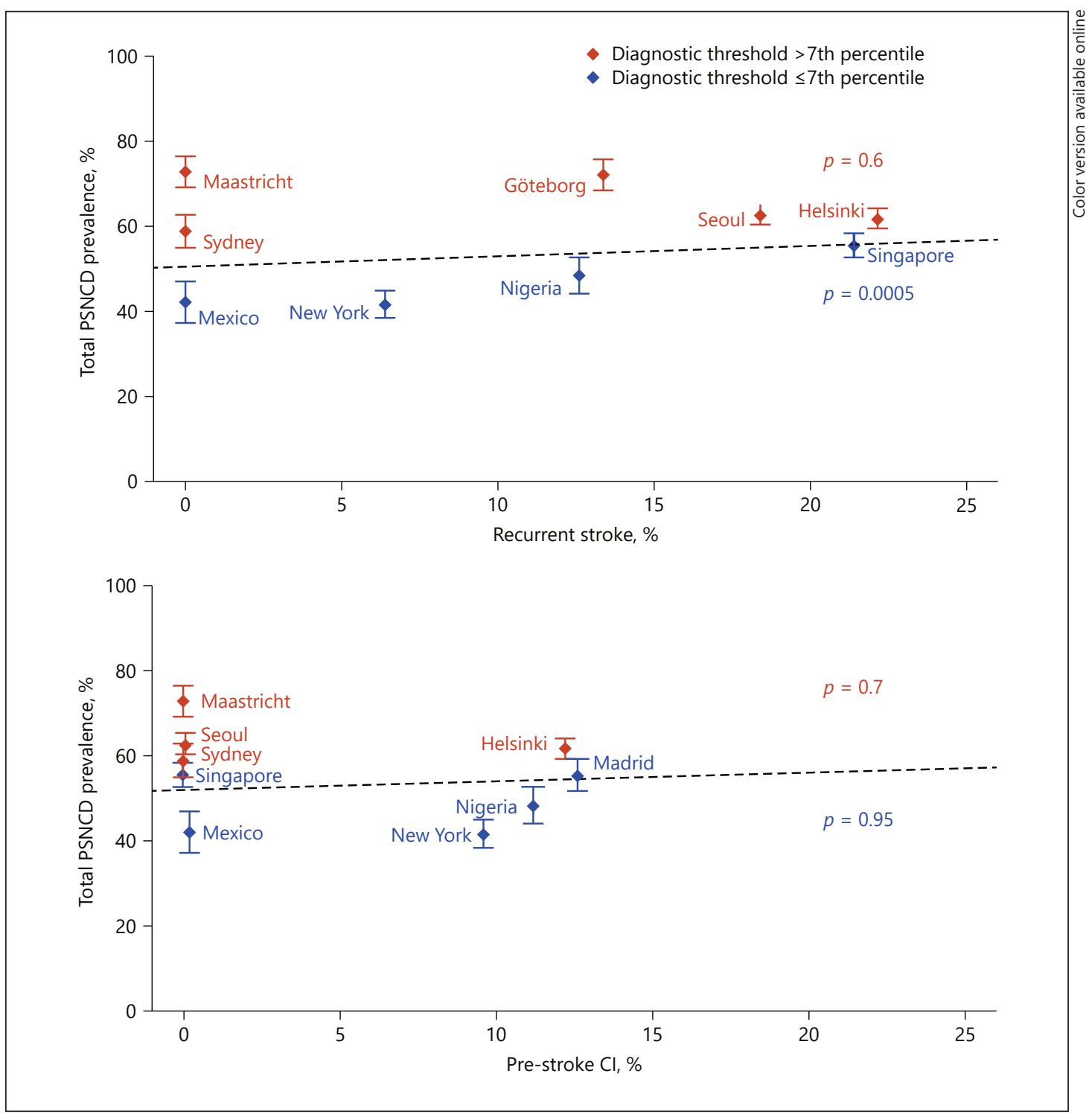

Fig. 4. Effect of the recurrent stroke rate (top) and pre-stroke dementia (bottom) on the overall prevalence of post-stroke neurocognitive disorders (PSNCD) according to threshold. CI, cognitive impairment.

dency, and institutionalization $[3,4]$. The present study also showed that about two-thirds of patients with NCD experienced mild post-stroke NCD and that failure to take these cases into account would seriously underestimate the impact of NCD. Finally, mild NCD could constitute a more appropriate target for future trials, justifying a more thorough analysis of this entity. The present pooled estimation of major post-stroke NCD was similar to that reported in a previous meta-analysis focusing on hospital-based cohorts with the exclusion of pre-stroke dementia (20.3\%) [2], which can be partly explained by the predominance of studies excluding patients with pre-stroke dementia in our pooled analysis.

Another major result of this study was the marked heterogeneity across studies of the estimated prevalence of mild, major, and total NCD. This heterogeneity cannot be attributed to differences in the classification of cognitive impairment into mild or major subtypes, i.e., diagnostic criteria of dementia, as it was also observed for the overall prevalence of NCD. A 
large proportion of the variability of the prevalence of total post-stroke NCD across studies can be attributed to methodological differences, especially the threshold $(\leq 7$ th percentile or not) used to determine cognitive impairment and, to a lesser extent, the interval between stroke and neuropsychological assessment. The use of a less conservative threshold (i.e., $>7$ th percentile) was associated with a 14\% increment of the estimated prevalence of total NCD. To our knowledge, this major effect has never been previously reported and is consistent with previous studies demonstrating the role of four methodological factors influencing the resulting prevalence of cognitive impairment: control for demographic factors (particularly age and education), procedures controlling for the false-positive rate (adjustment of the number of unpaired scores, computation of domain scores or global score), the size of the control group used to determine the cutoff score, and the threshold used to categorize cognitive score as normal versus impaired [45-47]. Eight studies used norms based on a control group: only 6 of these studies indicated the sample size of this group, which was greater than 500 in only 1 study, indicating that at least 5 , and possibly 7 , of the 8 studies were at risk of inaccurate determination of the cutoff and consequently inaccurate estimation of the prevalence of post-stroke NCD [45-58]. The effect of post-stroke interval supports the previous observation of an increased incidence of dementia according to post-stroke interval [2]. Heterogeneity was also related to casemix, which was significant only for age and prevalence of major NCD, supporting the previously reported older age of patients with post-stroke dementia [2]. The recurrent stroke rate also influenced the prevalence of total post-stroke NCD in the subgroup of studies using a threshold $\leq 7$ th percentile, which is consistent with previous reports of a higher prevalence of post-stroke dementia in patients with recurrent stroke [2]. Inversely, low education level and the prevalence of pre-stroke dementia were not statistically significant despite their association with variability $>20 \%$, in contrast with the effect of these factors in major post-stroke NCD [2], which is probably due to multiple sources of heterogeneity, as illustrated by the wide variation of coefficient estimates.

Our study presents several limitations. Heterogeneity was very marked, mainly due to methodological and casemix differences. Several studies also failed to provide details concerning factors influencing the prevalence of NCD, resulting in a smaller population included in meta-regression analyses, which may have biased our results. Nevertheless, this study provides pooled estimates based on the inclusion of studies performed in various countries all over the world. We deliberately focused on hospital-based cohorts and did not include population-based series, as hospital-based cohorts correspond to populations of stroke patients entering a management circuit designed to reduce disability. In addition, diagnosis on mild NCD requires a comprehensive neuropsychological assessment which is hardly performed in stroke patients that are not initially managed in hospital. Finally, our study did not examine the mechanisms of NCD, especially the possible contribution of associated Alzheimer's disease. Although some studies classified the causes of major post-stroke NCD, this classification remains very variable from one study to another and therefore tends to be unreliable.

The major finding of the present study is that half of stroke survivors experience some degree of post-stroke NCD several months post-stroke: two-thirds of them experience mild NCD and one-third experience major NCD. The prevalence of post-stroke NCD increases with age, recurrent stroke rate and, to a lesser degree, with post-stroke interval. This result has major implications for the organization of post-stroke care. The role of the cognitive impairment threshold and, more generally, the heterogeneity of post-stroke NCD across studies also have major implications for future studies, indicating the need for standardization of the assessment of post-stroke cognitive status in line with the Harmonization Standards groups [49]. The present study suggests four major sources of improvement. The first is the need to identify easily in routine practice patients at risk of cognitive impairment 
requiring comprehensive assessment. The second concerns the adoption of a standardized cognitive assessment according to the proposed neuropsychological battery assessing 5 cognitive domains (language, visuo-constructive abilities, memory, action speed, and executive functions), in addition to depression and behavioral changes [49]. The third source of improvement concerns the standardized analysis of a combination of cognitive scores, as proposed in a recent validation study [45]. Finally, common criteria for mild and major poststroke NCD must be adopted, as recently proposed by the VASCOG group [50]. Within the VASCOG criteria, harmonization of the threshold used to determine cognitive impairment will be an important point considering its major influence on the diagnosis of cognitive deficit. The recent finding that the 5th percentile threshold applied to a global cognitive score provides the highest sensitivity and specificity among various deficit criteria [51] may contribute to this objective.

\section{Acknowledgments}

We thank H. Berrissoul for help with the practical organization of the study. This study was funded by Amiens University Hospital and a grant from the French Health Department (DGOS R1/2013/144).

\section{Disclosure Statement}

Dr. Mélanie Barbay, Mrs. Martine Roussel, and Mr. Momar Diouf report no disclosure. Prof. Olivier Godefroy received remuneration for serving on a scientific advisory board from Novartis, for travel funding or speaking from Lilly, Genzyme, TEVA, Pfizer, Boerhinger, IPSEN, Covidien, and Bristol-Myers Squibb, for serving on the scientific board of Revue de Neuropsychologie Editorial Board and Frontiers in Human Neuroscience, and as a consultant for Pharnext.

\section{Author Contributions}

Mélanie Barbay and Olivier Godefroy performed the literature search, figure production, study design, data collection, data analysis, data interpretation, and writing. Momar Diouf carried out the figure production, data analysis, data interpretation, and writing. Martine Roussel conducted the study design. Other members of the GRECOGVASC study group took part in data collection.

\section{GRECOGVASC Study Group}

Olivier Godefroy, MD, PhD (Department of Neurology and Laboratory of Functional Neurosciences, University Hospital of Amiens, France); Martine Roussel , PhD (Department of Neurology and Laboratory of Functional Neurosciences, University Hospital of Amiens, France); Mélanie Barbay, MD (Department of Neurology and Laboratory of Functional Neurosciences, University Hospital of Amiens, France); Sandrine Canaple, MD (Department of Neurology and Laboratory of Functional Neurosciences, University Hospital of Amiens, France); Chantal Lamy, MD (Department of Neurology and Laboratory of Functional Neurosciences, University Hospital of Amiens, France); Claire Leclercq, MD (Department of Neurology and Laboratory of Functional Neurosciences, University Hospital of Amiens, France); Audrey Arnoux, MD (Department of Neurology and Laboratory of Functional Neurosciences, University Hospital of Amiens, France); Sandrine Despretz-Wannepain (Department of Neurology, University Hospital of Amiens, France); Pascal Despretz (University of Lille, INSERM CIC-IT 807, France); Hassan Berrissoul (University Hospital of Amiens, France); Carl Picard (Department of Biostatistics and medical research, University Hospital of Amiens, France); Momar Diouf (Department of Biostatistics and medical research, University Hospital of Amiens, France); Gwénolé Loas, MD, PhD (Department of Psychiatry and Laboratory of Functional Neurosciences, University Hospital of Amiens, France); Hervé Deramond, MD (Department of Radiology, University Hospital of Amiens, 
Barbay et al.: Meta-Analysis of Post-Stroke Cognitive Disorders

France); Hervé Taillia, MD (Department of Neurology, Val de Grace Hospital, Paris, France); Anne-Emmanuelle Ardisson(Department of Neurology, Val de Grace Hospital, Paris, France); Claudine Nédélec-Ciceri , MD (Department of Neurology, Hospital of La Rochelle, France); Camille Bonnin, PhD (Department of Neurology, Hospital of La Rochelle, France); Catherine Thomas-Anterion, MD, PhD (Department of Neurology, University Hospital of StEtienne, France); Francoise Vincent-Grangette (Department of Neurology and CMRR, University Hospital of St Etienne, France); Jérome Varvat, MD (Department of Neurology, University Hospital of St Etienne, France); Véronique Quaglino, PhD (Department of Psychology and Laboratory CRPPCO, University of Amiens, France); Hélène Beaunieux (Department of Psychology, University of Caen, France); Christine Moroni (Department of Psychology, University of Lille, France); Audrey Martens-Chazelles (Department of Neurology, Hospital of Creil, France); Stéphanie Batier-Monperrus (Department of Neurology, Hospital of Epinal, France); Cécile Monteleone and Véronique Costantino (Department of Neurology, Hospital of Ajaccio, France; Eric Theunssens (Institut de logopédie, Haute Ecole de Liège, Belgium).

\section{References}

1 Leys D, Hénon H, Mackowiak-Cordoliani MA, Pasquier F. Poststroke dementia. Lancet Neurol. 2005 Nov;4(11): 752-9.

2 Pendlebury ST, Rothwell PM. Prevalence, incidence, and factors associated with pre-stroke and post-stroke dementia: a systematic review and meta-analysis. Lancet Neurol. 2009 Nov;8(11):1006-18.

3 Tatemichi TK, Desmond DW, Stern Y, Paik M, Sano M, Bagiella E. Cognitive impairment after stroke: frequency, patterns, and relationship to functional abilities. J Neurol Neurosurg Psychiatry. 1994 Feb;57(2):202-7.

4 Rockwood K, Wentzel C, Hachinski V, Hogan DB, MacKnight C, McDowell I; Vascular Cognitive Impairment Investigators of the Canadian Study of Health and Aging. Prevalence and outcomes of vascular cognitive impairment. Neurology. 2000 Jan;54(2):447-51.

5 Stroup DF, Berlin JA, Morton SC, Olkin I, Williamson GD, Rennie D, et al. Meta-analysis of observational studies in epidemiology: a proposal for reporting. Meta-analysis Of Observational Studies in Epidemiology (MOOSE) group. JAMA. 2000 Apr 19;283(15):2008-12

6 DerSimonian R, Kacker R. Random-effects model for meta-analysis of clinical trials: an update. Contemp Clin Trials. 2007 Feb;28(2):105-14.

7 Cochran WG. The combination of estimates from different experiments. Biometrics. 1954;10(1):101-29.

8 Egger M, Davey Smith G, Schneider M, Minder C. Bias in meta-analysis detected by a simple, graphical test. BMJ. 1997 Sep;315(7109):629-34.

9 Thompson SG, Higgins JP. How should meta-regression analyses be undertaken and interpreted? Stat Med. 2002 Jun;21(11):1559-73.

10 Garcia PY, Roussel M, Bugnicourt JM, Lamy C, Canaple S, Peltier J, et al. Cognitive impairment and dementia after intracerebral hemorrhage: a cross-sectional study of a hospital-based series. J Stroke Cerebrovasc Dis. 2013 Jan;22(1):80-6.

11 Wong A, Xiong YY, Wang D, Lin S, Chu WW, Kwan PW, et al. The NINDS-Canadian stroke network vascular cognitive impairment neuropsychology protocols in Chinese. J Neurol Neurosurg Psychiatry. 2013 May;84(5): 499-504.

12 Tham W, Auchus AP, Thong M, Goh ML, Chang HM, Wong MC, et al. Progression of cognitive impairment after stroke: one year results from a longitudinal study of Singaporean stroke patients. J Neurol Sci. 2002 Nov; 203-204:49-52.

13 Garrett KD, Browndyke JN, Whelihan W, Paul RH, DiCarlo M, Moser DJ, et al. The neuropsychological profile of vascular cognitive impairment-no dementia: comparisons to patients at risk for cerebrovascular disease and vascular dementia. Arch Clin Neuropsychol. 2004 Sep;19(6):745-57.

14 Graham NL, Emery T, Hodges JR. Distinctive cognitive profiles in Alzheimer's disease and subcortical vascular dementia. J Neurol Neurosurg Psychiatry. 2004 Jan;75(1):61-71.

15 Vakhnina NV, Nikitina LY, Parfenov VA, Yakhno NN. Post-stroke cognitive impairments. Neurosci Behav Physiol. 2009 Oct;39(8):719-24.

16 Pustokhanova L, Morozova E. Cognitive impairment and hypothymia in post stroke patients. J Neurol Sci. 2013 Feb;325(1-2):43-5.

17 Lin JH, Lin RT, Tai CT, Hsieh CL, Hsiao SF, Liu CK. Prediction of poststroke dementia. Neurology. 2003 Aug; 61(3):343-8.

18 Sibolt G, Curtze S, Melkas S, Putaala J, Pohjasvaara T, Kaste M, et al. Poststroke dementia is associated with recurrent ischaemic stroke. J Neurol Neurosurg Psychiatry. 2013 Jul;84(7):722-6.

19 Melkas S, Oksala NK, Jokinen H, Pohjasvaara T, Vataja R, Oksala A, et al. Poststroke dementia predicts poor survival in long-term follow-up: influence of prestroke cognitive decline and previous stroke. J Neurol Neurosurg Psychiatry. 2009 Aug;80(8):865-70.

20 Oksala NK, Jokinen H, Melkas S, Oksala A, Pohjasvaara T, Hietanen M, et al. Cognitive impairment predicts poststroke death in long-term follow-up. J Neurol Neurosurg Psychiatry. 2009 Nov;80(11):1230-5. 
Barbay et al.: Meta-Analysis of Post-Stroke Cognitive Disorders

21 Barba R, Morin MD, Cemillán C, Delgado C, Domingo J, Del Ser T. Previous and incident dementia as risk factors for mortality in stroke patients. Stroke. 2002 Aug;33(8):1993-8.

22 Arpa A, del Ser T, Goda G, Barba R, Bornstein B. Apolipoprotein E, angiotensin-converting enzyme and alpha1-antichymotrypsin genotypes are not associated with post-stroke dementia. J Neurol Sci. 2003 Jun;210(1-2): 77-82.

23 del Ser T, Barba R, Morin MM, Domingo J, Cemillan C, Pondal M, et al. Evolution of cognitive impairment after stroke and risk factors for delayed progression. Stroke. 2005 Dec;36(12):2670-5.

24 Hénon H, Durieu I, Lebert F, Pasquier F, Leys D. Influence of prestroke dementia on early and delayed mortality in stroke patients. J Neurol. 2003 Jan;250(1):10-6.

25 Pasquier F, Hénon H, Leys D. Relevance of white matter changes to pre- and poststroke dementia. Ann NY Acad Sci. 2000 Apr; 903:466-9.

26 Cordonnier C, Hénon H, Derambure P, Pasquier F, Leys D. Early epileptic seizures after stroke are associated with increased risk of new-onset dementia. J Neurol Neurosurg Psychiatry. 2007 May;78(5):514-6.

27 Cordoliani-Mackowiak MA, Hénon H, Pruvo JP, Pasquier F, Leys D. Poststroke dementia: influence of hippocampal atrophy. Arch Neurol. 2003 Apr;60(4):585-90.

28 Zhou DH, Wang JY, Li J, Deng J, Gao C, Chen M. Study on frequency and predictors of dementia after ischemic stroke: the Chongqing stroke study. J Neurol. 2004 Apr;251(4):421-7.

29 Klimkowicz-Mrowiec A, Dziedzic T, Słowik A, Szczudlik A. Predictors of poststroke dementia: results of a hospital-based study in poland. Dement Geriatr Cogn Disord. 2006;21(5-6):328-34.

30 Tang WK, Chan SS, Chiu HF, Ungvari GS, Wong KS, Kwok TC, et al. Frequency and determinants of prestroke dementia in a Chinese cohort. J Neurol. 2004 May;251(5):604-8.

31 Mok VC, Wong A, Lam WW, Fan YH, Tang WK, Kwok T, et al. Cognitive impairment and functional outcome after stroke associated with small vessel disease. J Neurol Neurosurg Psychiatry. 2004 Apr; 75(4):560-6.

32 de Koning I, Dippel DW, van Kooten F, Koudstaal PJ. A short screening instrument for poststroke dementia : the R-CAMCOG. Stroke. 2000 Jul;31(7):1502-8.

33 Reitz C, Bos MJ, Hofman A, Koudstaal PJ, Breteler MM. Prestroke cognitive performance, incident stroke, and risk of dementia: the Rotterdam Study. Stroke. 2008 Jan;39(1):36-41.

34 Pendlebury ST, Mariz J, Bull L, Mehta Z, Rothwell PM. MoCA, ACE-R, and MMSE versus the National Institute of Neurological Disorders and Stroke-Canadian Stroke Network Vascular Cognitive Impairment Harmonization Standards Neuropsychological Battery after TIA and stroke. Stroke. 2012 Feb;43(2):464-9.

35 Stebbins GT, Nyenhuis DL, Wang C, Cox JL, Freels S, Bangen K, et al. Gray matter atrophy in patients with ischemic stroke with cognitive impairment. Stroke. 2008 Mar;39(3):785-93.

36 Schaapsmeerders P, Maaijwee NA, van Dijk EJ, Rutten-Jacobs LC, Arntz RM, Schoonderwaldt HC, Dorresteijn LD, Kessels RP, de Leeuw FE. Long-term cognitive impairment after first-ever ischemic stroke in young adults. Stroke. 2013 Jun;44(6):1621-8. DOI: 10.1161/StrokeAHA.111.000792.

37 Dong Y, Slavin MJ, Chan BP, Venketasubramanian N, Sharma VK, Crawford JD, et al. Cognitive screening improves the predictive value of stroke severity scores for functional outcome 3-6 months after mild stroke and transient ischaemic attack: an observational study. BMJ Open. 2013 Sep;3(9):e003105.

38 Narasimhalu K, Ang S, De Silva DA, Wong MC, Chang HM, Chia KS, et al. The prognostic effects of poststroke cognitive impairment no dementia and domain-specific cognitive impairments in nondisabled ischemic stroke patients. Stroke. 2011 Apr;42(4):883-8.

39 Kandiah N, Wiryasaputra L, Narasimhalu K, Karandikar A, Marmin M, Chua EV, et al. Frontal subcortical ischemia is crucial for post stroke cognitive impairment. J Neurol Sci. 2011 Oct;309(1-2):92-5.

40 Yu KH, Cho SJ, Oh MS, Jung S, Lee JH, Shin JH, et al.; Korean-Vascular Cognitive Impairment Harmonization Standards Study Group. Cognitive impairment evaluated with Vascular Cognitive Impairment Harmonization Standards in a multicenter prospective stroke cohort in Korea. Stroke. 2013 Mar;44(3):786-8.

41 Cho SJ, Yu KH, Oh MS, Jung S, Lee JH, Koh IS, et al.; Korean-Vascular Cognitive Impairment Harmonization Standards Study Group. Post-stroke memory impairment among patients with vascular mild cognitive impairment. BMC Neurol. 2014 Dec;14(1):244.

42 Wagle J, Farner L, Flekkøy K, Wyller TB, Sandvik L, Eiklid KL, et al. Cognitive impairment and the role of the ApoE epsilon4-allele after stroke-a 13 months follow-up study. Int J Geriatr Psychiatry. 2010 Aug;25(8): 833-42.

43 Hochstenbach J, Mulder T, van Limbeek J, Donders R, Schoonderwaldt H. Cognitive decline following stroke: a comprehensive study of cognitive decline following stroke. J Clin Exp Neuropsychol. 1998 Aug;20(4):50317.

44 Altieri M, Di Piero V, Pasquini M, Gasparini M, Vanacore N, Vicenzini E, et al. Delayed poststroke dementia: a 4-year follow-up study. Neurology. 2004 Jun;62(12):2193-7.

45 Godefroy O, Gibbons L, Diouf M, Nyenhuis D, Roussel M, Black S, et al.; GREFEX study group. Validation of an integrated method for determining cognitive ability: implications for routine assessments and clinical trials. Cortex. 2014 May;54:51-62.

46 Brooks BL, Iverson GL. Comparing actual to estimated base rates of "abnormal" scores on neuropsychological test batteries: implications for interpretation. Arch Clin Neuropsychol. 2010 Feb;25(1):14-21.

47 Crawford JR, Garthwaite PH, Gault CB. Estimating the percentage of the population with abnormally low scores (or abnormally large score differences) on standardized neuropsychological test batteries: a generic method with applications. Neuropsychology. 2007 Jul;21(4):419-30. 
Barbay et al.: Meta-Analysis of Post-Stroke Cognitive Disorders

48 Godefroy O, Diouf M, Bigand C, Roussel M. Neurocognitive disorders of mild severity or performance in the low normal range? Urgent need for a standardization of criteria of neurocognitive impairment and their operationalization. Rev Neuropsychol. 2014;6:159-62.

49 Hachinski V, Iadecola C, Petersen RC, Breteler MM, Nyenhuis DL, Black SE, et al. National Institute of Neurological Disorders and Stroke-Canadian Stroke Network vascular cognitive impairment harmonization standards. Stroke. 2006 Sep;37(9):2220-41.

50 Sachdev P, Kalaria R, O’Brien J, Skoog I, Alladi S, Black SE, et al.; Internationlal Society for Vascular Behavioral and Cognitive Disorders. Diagnostic criteria for vascular cognitive disorders: a VASCOG statement. Alzheimer Dis Assoc Disord. 2014 Jul-Sep;28(3):206-18.

51 Barbay M, Taillia H, Nédélec-Ciceri C, Bompaire F, Bonnin C, Varvat J, et al.; GRECOG-VASC Study Group. Prevalence of Poststroke Neurocognitive Disorders Using National Institute of Neurological Disorders and StrokeCanadian Stroke Network, VASCOG Criteria (Vascular Behavioral and Cognitive Disorders), and Optimized Criteria of Cognitive Deficit. Stroke. 2018 May;49(5):1141-7.

52 Tatemichi TK, Desmond DW, Paik M, Figueroa M, Gropen TI, Stern Y, et al. Clinical determinants of dementia related to stroke. Ann Neurol. 1993 Jun;33(6):568-75.

53 Rasquin SM, Lodder J, Ponds RW, Winkens I, Jolles J, Verhey FR. Cognitive functioning after stroke: a one-year follow-up study. Dement Geriatr Cogn Disord. 2004;18(2):138-44.

54 Censori B, Manara O, Agostinis C, Camerlingo M, Casto L, Galavotti B, et al. Dementia after first stroke. Stroke. 1996 Jul;27(7):1205-10.

55 Pohjasvaara T, Erkinjuntti T, Vataja R, Kaste M. Dementia three months after stroke. Baseline frequency and effect of different definitions of dementia in the Helsinki Stroke Aging Memory Study (SAM) cohort. Stroke. 1997 Apr;28(4):785-92.

56 Madureira S, Guerreiro M, Ferro JM. Dementia and cognitive impairment three months after stroke. Eur J Neurol. 2001 Nov;8(6):621-7.

57 Serrano S, Domingo J, Rodríguez-Garcia E, Castro MD, del Ser T. Frequency of cognitive impairment without dementia in patients with stroke: a two-year follow-up study. Stroke. 2007 Jan;38(1):105-10.

58 Sachdev PS, Brodaty H, Valenzuela MJ, Lorentz L, Looi JC, Wen W, et al. The neuropsychological profile of vascular cognitive impairment in stroke and TIA patients. Neurology. 2004 Mar;62(6):912-9.

59 Arauz A, Rodríguez-Agudelo Y, Sosa AL, Chávez M, Paz F, González M, et al. Vascular cognitive disorders and depression after first-ever stroke: the Fogarty-Mexico Stroke Cohort. Cerebrovasc Dis. 2014;38(4):284-9.

60 Saini M, Tan CS, Hilal S, Dong Y, Ting E, Ikram MK, et al. Computer tomography for prediction of cognitive outcomes after ischemic cerebrovascular events. J Stroke Cerebrovasc Dis. 2014 Aug;23(7):1921-7.

61 Ihle-Hansen H, Thommessen B, Wyller TB, Engedal K, Øksengård AR, Stenset V, et al. Incidence and subtypes of MCI and dementia 1 year after first-ever stroke in patients without pre-existing cognitive impairment. Dement Geriatr Cogn Disord. 2011;32(6):401-7.

62 Lindén T, Skoog I, Fagerberg B, Steen B, Blomstrand C. Cognitive impairment and dementia 20 months after stroke. Neuroepidemiology. 2004 Jan-Apr;23(1-2):45-52.

63 Delgado C, Donoso A, Orellana P, Vásquez C, Díaz V, Behrens MI. Frequency and determinants of poststroke cognitive impairment at three and twelve months in Chile. Dement Geriatr Cogn Disord. 2010;29(5):397-405.

64 Chaudhari TS, Verma R, Garg RK, Singh MK, Malhotra HS, Sharma PK. Clinico-radiological predictors of vascular cognitive impairment (VCI) in patients with stroke: a prospective observational study. J Neurol Sci. 2014 May; 340(1-2):150-8.

65 Akinyemi RO, Allan L, Owolabi MO, Akinyemi JO, Ogbole G, Ajani A, et al. Profile and determinants of vascular cognitive impairment in African stroke survivors: the CogFAST Nigeria Study. J Neurol Sci. 2014 Nov;346(12):241-9. 